\title{
Calcium-dependent release of accumulated glutamate from synaptic vesicles within permeabilized nerve terminals
}

\author{
Phillip E. Kish ${ }^{1}$ and Tetsufumi Ueda ${ }^{1,2}$ \\ ${ }^{1}$ Mental Health Research Institute and ${ }^{2}$ Departments of Pharmacology and Psychiatry, The University of Michigan, Ann Arbor, MI 48109 (U.S.A.)
}

(Received 9 April 1990; Revised version received 16 October 1990; Accepted 16 October 1990)

Key words: Synaptic vesicle; Neurotransmitter release; Calcium-dependent; Glutamate; ATP-dependent uptake

\begin{abstract}
We have studied glutamate release from synaptic vesicles in permeabilized synaptosomes, which were preloaded with [ $\left.{ }^{3} \mathrm{H}\right] \mathrm{glutamate}$ in an ATPdependent manner. The release was found to be calcium-dependent and to require a heat-labile cytosolic macromolecule factor for maximum activity. Maximal release occurred at $5 \mu \mathrm{M}$ free $\mathrm{Ca}^{2+}$ and within $5 \mathrm{~min}$. Of the other divalent cations tested, only barium stimulated release of vesicular glutamate. The release was inhibited by $N$-ethylmaleimide. These results are characteristic of exocytotic release of monoamines and peptides observed in endocrine systems, and constitute direct evidence for the notion that calcium-dependent release of glutamate originates from the vesicular pool.
\end{abstract}

Amassed evidence indicates that glutamate serves as a major excitatory neurotransmitter in the vertebrate central nervous system (for review, see ref. 4). Despite the increased recognition of the neurotransmitter role of glutamate, the mechanism by which glutamate is released from the nerve terminal remains in large part to be elucidated. Substantial evidence now has been accumulated that glutamate is specifically taken up into highly purified isolated synaptic vesicles in an ATP-dependent manner $[6,8,12,15-18,22]$, suggesting that glutamate could be accumulated and stored in synaptic vesicles in vivo. This is in accord with immunocytochemical evidence provided by Storm-Mathisen et al. [21] suggesting that glutamate is concentrated in certain synaptic vesicles distinct from $\gamma$-aminobutyric acid (GABA)-containing vesicles. Recent evidence has indicated that glutamate released in a calcium-dependent manner originates from a non-cytoplasmic pool [20]. These lines of evidence argue for the involvement of synaptic vesicles in synaptic release of glutamate. In this study, we have investigated the calcium-dependent release of glutamate from the synaptic vesicles in a more direct manner, using a permeabilized synaptosome preparation. Evidence is presented that glutamate is indeed released directly from the synaptic vesicle in a calcium-dependent manner, in the presence of a cytosolic factor.

Correspondence: T. Ueda, Mental Health Research Institute, The University of Michigan, 205 Washtenaw Place, Ann Arbor, MI 48109, U.S.A.
Synaptosomes were prepared from the rat (60 to $90-$ day-old) cerebrum according to the method of Hajos [9], and resuspended in $0.32 \mathrm{M}$ sucrose at a concentration of $25 \mathrm{mg} / \mathrm{ml}$. One $\mathrm{ml}$ aliquots were frozen in liquid nitrogen and thawed. The freeze/thaw step was repeated twice more to permeabilize the nerve terminal plasma membrane. Synaptic vesicles maintain ATP-dependent glutamate uptake activity even after freeze/thawing [12, 17] while synaptosomal plasma membranes are ruptured. A synaptosomal cytosol fraction was prepared from rat brain as described [23] followed by $40 \%$ ammonium sulfate precipitation. This precipitated pellet was resuspended, dialyzed with $10 \mathrm{mM}$ Tris-maleate $\mathrm{pH} \mathrm{7.0, \text {and }}$ used as a partly purified cytosolic factor.

Permeabilized synaptosomes were subjected to ATPdependent glutamate uptake under conditions modified from those described for vesicular uptake [18]. The incubation mixture contained in a final volume of $0.12 \mathrm{ml}$ : permeabilized synaptosomes (250 $\mu \mathrm{g}$ protein), $10 \mathrm{mM}$ Tris-maleate ( $\mathrm{pH} 7.2), 4 \mathrm{mM} \mathrm{KCl}, 200 \mathrm{mM}$ sucrose, 0.5 $\mathrm{mM}$ ouabain, $10 \mathrm{mM}$ glucose, $20 \mathrm{mM}$ aspartate (to minimize $\mathrm{Na}^{+}$-dependent uptake and binding to glutamate receptors), $2 \mathrm{mM}$ EGTA, $15 \mathrm{mM} \mathrm{MgSO}_{4}, 9 \mathrm{mM}$ ATP, synaptosol factor (330 $\mu \mathrm{g}$ protein) and $5 \mu \mathrm{M}$ potassium $\left[{ }^{3} \mathrm{H}\right] \mathrm{L}$-glutamate $(0.8 \mathrm{Ci} / \mathrm{mmol})$. The ATP-dependent uptake reached a plateau by $10 \mathrm{~min}$ at $37^{\circ} \mathrm{C}$, and the level was maintained for an additional $5 \mathrm{~min}$. To study release of accumulated glutamate from permeabilized synaptosomes, $5 \mu \mathrm{l}$ of buffer or $\mathrm{Ca}^{2+}$-containing buffer solution were added to each tube at the end of $10 \mathrm{~min}$ of uptake, and the incubation was allowed to continue 


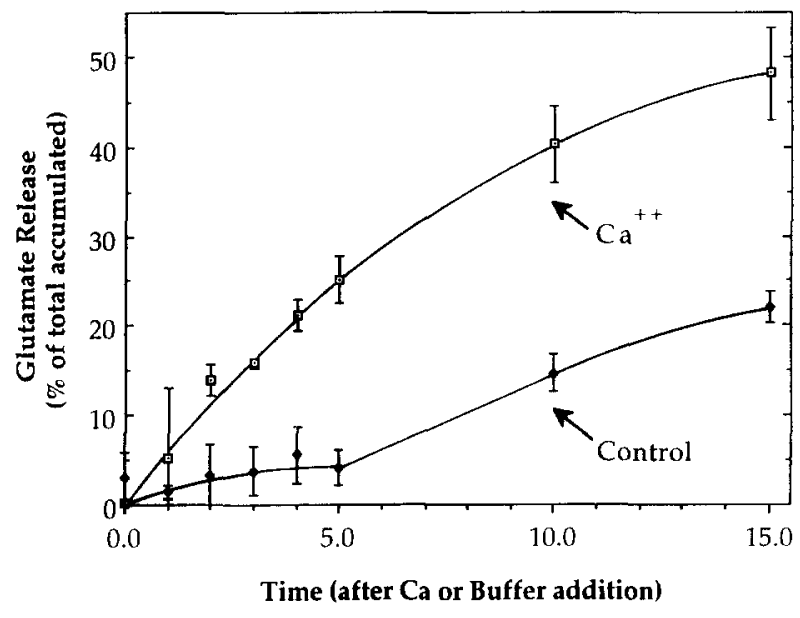

Fig. 1. Time course of glutamate from permeabilized synaptosomes. Permeabilized synaptosomes were loaded with $\left[{ }^{3} \mathrm{H}\right]$ glutamate in the presence of ATP and a partially purified cytosolic factor, as described in the text, and further incubated for release for various periods of time in the presence or absence of calcium ( $5 \mu \mathrm{M}$ free $\left.\mathrm{Ca}^{2+}\right)$. The absence of calcium indicates the presence of 2 mM EGTA (free $\mathrm{Ca}^{2+}$, less than $0.1 \mu \mathrm{M})$. The data represent mean \pm S.E.M. obtained from experiments using 3 separate synaptosome and cytosolic factor preparations.

for 5 additional min. Each incubation was carried out in duplicate. Release was terminated by the addition of icecold $0.15 \mathrm{M} \mathrm{KCl}$, followed by filtration on a glass fiber filter (GF-C). The glutamate release was expressed as $\%$ of the total $\left[{ }^{3} \mathrm{H}\right]$ glutamate accumulated at the end of 10 min uptake as follows:

$$
\frac{\mathrm{Glu}_{10}-\mathrm{Glu}_{15}}{\mathrm{Glu}_{10}-\mathrm{Glu}_{10}^{\prime}} \times 100
$$

where $\mathrm{Glu}_{10}$ and $\mathrm{Glu}_{10}^{\prime}$ are the amounts of $\left[{ }^{3} \mathrm{H}\right] \mathrm{gluta}$ mate accumulated in the presence of ATP at 37 and $0^{\circ} \mathrm{C}$, respectively, during the $10 \mathrm{~min}$ incubation, and $\mathrm{Glu}_{15}$ is the amount of $\left[{ }^{3} \mathrm{H}\right]$ glutamate retained at $37^{\circ} \mathrm{C}$ (in the presence of ATP) at the end of the release period. The temperature-dependent glutamate uptake in the presence of ATP was considered here to be equivalent to the ATPdependent uptake at $37^{\circ} \mathrm{C}$, since the degree of ATP-dependency was essentially the same as that of temperature-dependency in highly purified synaptic vesicles [18]. We adopted this method because the true ATP-dependent uptake activity could not be accurately determined in the permeabilized synaptosome preparation due to endogenous ATP contamination in the preparation.

The time courses of calcium-dependent and calciumindependent vesicular release are shown in Fig. 1. The vesicular pool of glutamate taken up in an energy-dependent manner was released significantly upon addition of $\mathrm{Ca}^{2+}$. The $\mathrm{Ca}^{2+}$-dependent release was complete by 5 min. When the cytosolic factor was omitted from the

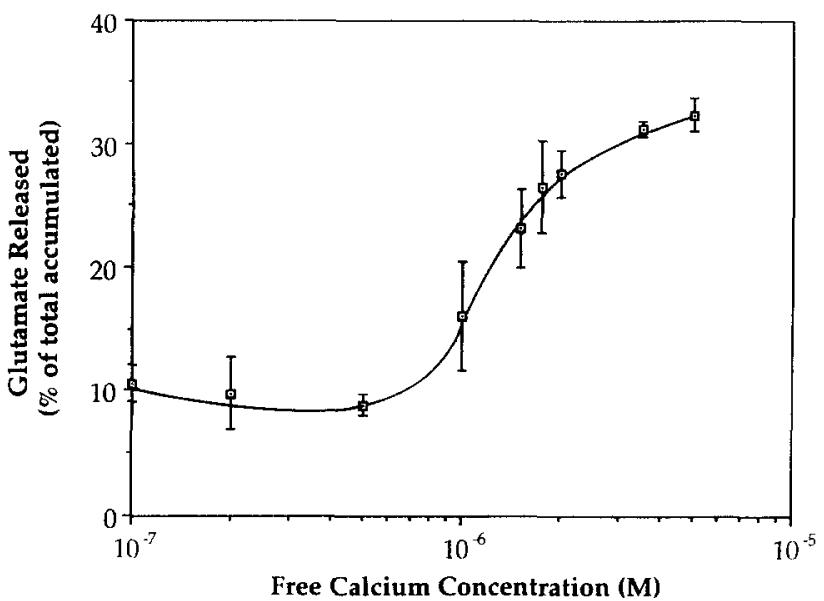

Fig. 2. Effect of various concentrations of calcium on glutamate release from permeabilized synaptosomes. The experiment was carried out as shown in Fig. 1, except that the free $\mathrm{Ca}^{2+}$ concentration was varied as indicated $(0.1,0.2,0.5,1,1.5,1.75,2,3.5$, and $5 \mu \mathrm{M})$, and that release was allowed to occur for $5 \mathrm{~min}$. Free calcium concentrations were determined using a calcium electrode calibrated against standard calcium solutions. The data represent mean \pm S.E.M. obtained from experiments using 3 separate synaptosome and cytosolic factor preparations.

incubation, calcium-dependent release was substantially reduced (data not shown).

Fig. 2 shows that the release is dependent on the calcium concentration; maximal release occurred at approximately $5 \mu \mathrm{M}$ free $\mathrm{Ca}^{2+}$. This concentration lies in the range of free $\mathrm{Ca}^{2+}$ concentration $(1-10 \mu \mathrm{M})$ which has been shown to give maximal release of other neurotransmitters and hormones, such as catecholamine from

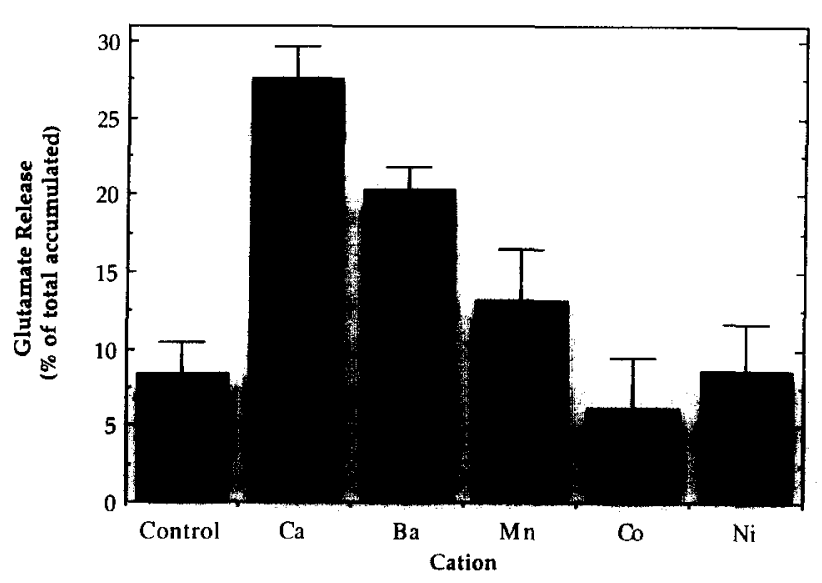

Fig. 3. Effect of various cations on glutamate release from permeabilized synaptosomes. The experiment was carried out as described in Fig. 1, except that various divalent cations were added each at $2.8 \mathrm{mM}$ in the presence of $2 \mathrm{mM}$ EGTA, at the beginning of the release period, and that release was terminated after $5 \mathrm{~min}$ incubation. For calcium, free $\mathrm{Ca}^{2+}$ was $3.5 \mu \mathrm{M}$. The data represent mean \pm S.E.M. obtained from experiments using 3 separate synaptosome and cytosolic factor preparations 
permeabilized chromaffin cells [5] and histamine from mast cells [10].

The stimulatory effect of $\mathrm{Ca}^{2+}$ was mimicked by $\mathrm{Ba}^{2+}$ but not by the other divalent cations tested, which include $\mathrm{Mg}^{2+}, \mathrm{Mn}^{2+}, \mathrm{Co}^{2+}$ and $\mathrm{Ni}^{2+}$ (Fig. 3). The divalent metal specificity is similar to that observed on catecholamine release from chromaffin granules [24]. Moreover, the $\mathrm{Ca}^{2+}$-dependent release was inhibited by the sulfhydryl blocking agent $N$-ethylmaleimide (NEM) (data not shown), as in the case with exocytotic release of catecholamine from digitonin-permeabilized chromaffin cells $[7,24]$.

The cytosolic factor was further purified by chromatography on DEAE-Bio Gel A $(150-200 \mathrm{mM} \mathrm{NaCl}$ eluate). In contrast to the permeabilized synaptosome preparation, isolated synaptic vesicles, which had been preloaded with $\left[{ }^{3} \mathrm{H}\right]$ glutamate in the presence of ATP, exhibited no increase in net efflux of glutamate, in the presence of this purified factor $(75 \mu \mathrm{g} / 0.125 \mu \mathrm{l})$ either in the presence or absence of $5 \mu \mathrm{M}$ free calcium (data not shown). This purified factor was also separated from a proteinaceous substance [13] causing a decrease in net uptake into isolated synaptic vesicles (data not shown). In other experiments, the factor was shown to be a heatlabile macromolecule with a molecular weight of greater than 135,000 (data not shown).

In this study, we have provided evidence that glutamate is released from synaptic vesicles within the permeabilized synaptosome in response to an increase in calcium concentration. The glutamate release required a synaptosol factor for maximal release. We suggest that this release represents a physiologically relevant calciumdependent release of glutamate, based upon the characteristics observed here which are similar to those observed on exocytotic release of catecholamine from chromaffin cells, histamine from mast cells, and prolactin from $\mathrm{GH}_{3}$ cells; these include (a) sensitivity to calcium $[1,5,10,14]$, (b) cation specificity [11, 24], (c) inhibition by NEM [7, 24], and (d) marked stimulation by a synaptosomal soluble factor [14].

Calcium-dependent glutamate release using brain slices and intact synaptosomes has been well documented (for review, see ref. 19). Nicholls and colleagues have provided evidence that the calcium-dependent release is derived from a non-cytoplasmic pool [20], potentially from the synaptic vesicle pool. Our study reported here provides direct evidence that the calcium-dependent release originates from the synaptic vesicle, further supporting the vital role of synaptic vesicle in glutamate synaptic transmission. This conclusion was possible to draw since the calcium-dependent release was derived from that pool into which glutamate had previously been accumulated in an ATP-dependent, chloride-stimulated manner.
The successful demonstration of calcium-dependent release of glutamate from the permeabilized nerve terminal required two conditions. One is that release experiments were carried out under conditions which maintain active vesicular uptake. This is important since accumulated glutamate exits from the synaptic vesicle as soon as ATP and glutamate are removed from the extravesicular medium $[2,3]$. The other condition was to fortify the release system with a cytosolic factor. It is interesting to note that a cytosolic protein is also required for the secretion of prolactin in a pituitary cell line [14].

The method described here or its modification provides a direct, simple biochemical assay for calcium-dependent vesicular release of glutamate, and may be useful for studying the molecular mechanism of exocytosis for glutamate and other neurotransmitters from the nerve terminal.

We are grateful to Dr. Joel Tabb for his comments on the manuscript. This study was supported by NIMH 5P01 MH 42652.

1 Baker, P.F. and Knight, D.E., Calcium-dependent exocytosis in bovine adrenal medullary cells with leaky plasma membranes, $\mathrm{Na}$ ture, 276 (1978) 620-622.

2 Carlson, M.D. and Ueda, T., Glutamate efflux from synaptic vesicles, J. Neurochem., 52 Suppl. (1989) S67C.

3 Carlson, M.D. and Ueda, T., Accumulated glutamate levels in the synaptic vesicle are not maintained in the absence of active transport, Neurosci. Lett., 110 (1990) 325-330.

4 Cotman, C.W., Bridges, R.J., Taube, J.S., Clark, A.S., Geddes, J.W. and Monaghan, D.T., The role of the NMDA receptor in central nervous system plasticity and pathology, J. NIH Res., 1 (1989) 65-74.

5 Dunn, L.A. and Holz, R.W., Catecholamine secretion from digitonin-treated adrenal medullary chromaffin cells, J. Biol. Chem., 258 (1983) 4989-4993.

6 Fischer-Bovenkerk, C., Kish, P.E. and Ueda, T., ATP-dependent glutamate uptake into synaptic vesicles from cerebellar mutant mice, J. Neurochem., 51 (1988) 1054-1059.

7 Frye, R.A. and Holz, R.W., Arachidonic acid release and catecholamine secretion from digitonin-treated chromaffin cells: effects of micromolar calcium, phorbol ester, and protein alkylating agents, J. Neurochem., 44 (1985) 265-273.

8 Fykse, E.M., Christensen, H. and Fonnum, F., Comparison of the properties of gamma-aminobutyric acid and L-glutamate uptake into synaptic vesicles isolated from rat brain, J. Neurochem., 52 (1989) 946-951.

9 Hajos, F., An improved method for the preparation of synaptosomal fractions in high purity, Brain Res., 93 (1975) 485-489.

10 Howell, T.W., Cockcroft, S. and Gomperts, B.D., Essential synergy between $\mathrm{Ca}^{2+}$ and guanine nucleotides in exocytotic secretion from permeabilized rat mast cells, J. Cell Biol., 105 (1987) 191197.

11 Izumi, F., Toyohira, Y., Yanagihara, N., Wada, A. and Kobayashi, H., Barium-evoked release of catecholamines from digitonin-permeabilized adrenal medullary cells, Neurosci. Lett., 69 (1986) 172-175. 
12 Kish, P.E. and Ueda, T., Glutamate accumulation into synaptic vesicles. In S. Fleischer and B. Fleischer, Biomembranes, Part U, Methods in Enzymology, 174, Academic Press, New York, 1989, pp. 9-25.

13 Lobur, A.T., Kish, P.E. and Ueda, T., Synaptic vesicular glutamate uptake: modulation by a synaptosomal cytosolic factor, J. Neurochem., 54 (1990) 1614-1618.

14 Martin, T.F. and Walent, J.H., A new method for cell permeabilization reveals a cytosolic protein requirement for $\mathrm{Ca}^{2+}$-activated secretion in $\mathrm{GH}_{3}$ pituitary cell, J. Biol. Chem., 264 (1989) 10299 10308.

15 Maycox, P.R., Deckwerth, T., Hell, J.W. and Jahn, R., Glutamate uptake by brain synaptic vesicles. Energy dependence of transport and functional reconstitution in proteoliposomes, J. Biol. Chem., 263 (1988) 15423-15428.

16 Maycox, P.R., Hell, J.W. and Jahn, R., Amino acid neurotransmission: spotlight on synaptic vesicles, Trends Neurosci., 13 (1990) 83 87.

17 Naito, S. and Ueda, T., Adenosine triphosphate-dependent uptake of glutamate into protein I-associated synaptic vesicles, J. Biol. Chem., 258 (1983) 696-699.
18 Naito, S. and Ueda, T., Characterization of glutamate uptake into synaptic vesicles, J. Neurochem., 44 (1985) 99-109.

19 Nicholls, D.G., Release of glutamate, aspartate, and gamma-aminobutyric acid from isolated nerve terminals [see comments], $\mathrm{J}$. Neurochem., 52 (1989) 331-341.

20 Nicholls, D.G. and Sihra, T.S., Synaptosomes possess an exocytotic pool of glutamate, Nature, 321 (1986) 772-773.

21 Storm-Mathisen, J., Leknes, A.K., Bore, A.T., Vaaland, J.L., Edminson, P., Haug, F.M. and Ottersen, O.P., First visualization of glutamate and GABA in neurones by immunocytochemistry, Nature, 301 (1983) 517-520.

22 Ueda, T., Glutamate transport in the synaptic vesicle. In P.J. Roberts, J. Storm-Mathisen and H.F. Bradford, Excitatory Amino Acids, Macmillan, London (1986), pp. 173-195.

23 Ueda, T. and Plagens, D.G., 3-Phosphoglycerate-dependent protein phosphorylation, Proc. Natl. Acad. Sci., 84 (1987) 1229-1233.

24 Wilson, S.P. and Kirshner, N., Calcium-evoked secretion from digitonin-permeabilized adrenal medullary chromaffin cells, J. Biol. Chem., 258 (1983) 4994-5000. 